\title{
Extended mind and artifactual autobiographical memory
}

\section{Richard Heersmink (1)}

Department of Politics, Media and Philosophy, La Trobe University, Melbourne, Victoria, Australia

\section{Correspondence}

Richard Heersmink, Department of Politics, Media and Philosophy, La Trobe University, Plenty Rd, Kingsbury

Dr. Bundoora, Melbourne, VIC 3086, Australia.

Email: r.heersmink@latrobe.edu.au

\begin{abstract}
In this paper, I describe how artifacts and autobiographical memory are integrated into new systemic wholes, allowing us to remember our personal past in a more reliable and detailed manner. After discussing some empirical work on lifelogging technology, I elaborate on the dimension of autobiographical dependency, which is the degree to which we depend on an object to be able to remember a personal experience. When this dependency is strong, we integrate information in the embodied brain and in an object to reconstruct an autobiographical memory. In such cases, autobiographical memory is extended or distributed.
\end{abstract}

\section{K E Y W O R D S}

autobiographical memory, cognitive integration, distributed memory, evocative objects, extended mind

\section{1 | INTRODUCTION}

The paradigm cases in extended and distributed cognition theories focus on the way artifacts are integrated into working memory, prospective memory, spatial memory, and semantic memory. Examples include making a calculation with pen and paper (Clark, 1989), remembering quantities of items with a knotted cord (Rowlands, 1999), navigating with maps (Hutchins, 1995), and remembering facts with a notebook (Clark \& Chalmers, 1998). Such uses of external artifacts are adaptive behaviors often enhancing our cognitive capacities, making cognitive tasks easier, faster, more reliable, or possible at all. Extended and distributed autobiographical remembering, however, seems to be largely absent from the literature. ${ }^{1}$ While extended and

\footnotetext{
${ }^{1}$ An elaborate Google Scholar search with the phrases "extended mind and autobiographical memory", "extended mind and episodic memory", "extended distributed cognition and autobiographical memory", "extended distributed cognition and episodic memory" resulted in one article (Clowes, 2013) that mentions the possibility of artifact-extended autobiographical memory in passing and one chapter (Sutton, 2009a, see also 2009b) that elaborates on the notion in more detail by suggesting that Leonard in the film Memento uses artifacts like annotated polaroids and tattoos to extend his autobiographical memory.
} 
distributed autobiographical memory has received significant attention in the social psychological theory of transactive memory (e.g., Harris, Barnier, Sutton \& Keil, 2014; Wegner, 1986), it is largely overlooked in the debate on the relation between cognizers and their artifactual environment.

The goal of this paper is therefore to draw attention to artifactual autobiographical remembering by discussing empirical work on evocative objects and lifelogging and by conceptualizing how such objects and technologies are integrated into biological memory processes, thereby changing the structure of our autobiographical memory (Bell \& Gemmell, 2009). When interacting with evocative objects, we typically integrate information in the brain and in the world to construct an autobiographical memory, thereby allowing us to remember our personal past in a way that is quite different from remembering our past without the aid of such objects. A particular focus in this paper is on the dimension of autobiographical dependency, which is the degree to which we depend on an object to be able to remember a personal experience. I will discuss various degrees of autobiographical dependency, ranging from low, to moderate, and to strong. The stronger this dependency, the more likely it is that both the vehicles and processes of remembering our personal past are extended and distributed.

This paper has the following structure. I start with identifying two arguments in favor of the extended mind, one based on parity and one on complementarity between an agent and external resource, prioritizing the latter (Section 2). I then taxonomize different human memory systems and briefly describe some of the properties of human autobiographical memory (Section 3). Next, I distinguish between cognitive artifacts used for practical cognitive tasks and evocative objects used for remembering our personal past, focusing on the latter (Section 4). I end this paper with conceptualizing the dimension of autobiographical dependency (Section 5) and conduct a case study where the degree of integration between agent and lifelogging technology is conceptualized (Section 6).

\section{2 | THE EXTENDED MIND}

Clark and Chalmers (1998) argue that minds and cognitive systems are not exclusively realized by brains but are sometimes realized by agent-artifact systems. A key example is Otto, a man with Alzheimer's disease using a notebook to remember information. Information in the notebook (e.g., an address) plays relevantly similar functional roles as information usually stored in semantic memory. The notebook is also easily available, reliable, the information in it is trustworthy, and is there because it has been endorsed in the past. It would be biochauvinistic, Clark (2008) says, to conceive of the notebook as a mere tool for Otto's biological memory. Instead, we should conceive of the notebook as a proper part of Otto's memory system. Other artifacts that satisfy these conditions (i.e., functional parity, availability, reliability, trust, and past endorsement) are, likewise, proper parts of our cognitive systems. On this view, the location of the vehicles of cognition is not important for their cognitive status. Rather, the functional role they play determines whether they are part of a cognitive system. The vehicles of cognitive states and processes can thus be located outside the organism, that is, in the wider environment (Rowlands, 1999; Wilson, 2004). The upshot of this claim is both ontological and methodological. Ontological, because material culture is (under certain circumstances) literally part of the physical supervenience base of minds and cognitive systems. Methodological, because to better understand such extended systems, we need to enlarge the unit of analysis in the cognitive sciences, studying how agents interact with their environment. 
There are two main arguments in favor of the extended mind, one based on functional parity between biological and artifactual resources (Clark \& Chalmers, 1998; Wheeler, 2011) and one based on the complementarity between biological and artifactual resources (Menary, 2007, Sutton, 2010; for a recent overview of these two arguments see Gallagher, 2018). Parity-based arguments have been criticized as empirically implausible as the informational properties and functions of cognitive artifacts are often quite different from those of internal states and processes (Heersmink, 2015; Menary, 2007; Sutton, 2010). Complementarity-based extended mind theory recognizes the differences between biological and artifactual resources in term of their informational properties, dynamics, and functions. If an artifact is to provide a cognitive benefit for an agent, it often has properties that the biological cognitive system of the agent lacks. We use a cognitive artifact when we cannot perform the task ourselves, that is, without the aid of an artifact.

Such artifacts with complementary properties and functions are integrated into biological cognitive systems to varying degrees. By synthesizing work of Clark and Chalmers (1998), Wilson and Clark (2009), Sutton (2010), and Sterelny (2010), Heersmink (2015) has suggested that the degree of integration between an agent's cognitive system and an environmental resource depends on a number of dimensions. These dimensions include the intensity of information flow, accessibility of the resource, durability of the relation between agent and artifact, trustworthiness of the information the artifact contains, procedural transparency or ease of use, informational transparency or level of informational understanding, and the degree of personalization. Such dimensions are matters of degree and describe certain properties of the cognitive relation between an embodied agent and an external resource. The higher an agent-artifact system scores on these dimensions, the tighter the integration between the agent's cognitive system and an artifact, thereby increasing the extendedness and distributedness. This multidimensional framework can be used to perform case studies of specific cognitive artifacts, conceptualizing the degree of integration (for discussion see Heinrich, 2018). It is, however, not always easy or even possible to demarcate clearly between the embedded and extended cases. The relations between embodied agents and artifacts can vary along many dimensions and are thus quite complex. For this reason, there is a grey area in between the paradigm cases of embedded and extended systems in which it may not always be clear whether a system is embedded or extended.

In the previous 25 years or so, the extended mind and the more empirically oriented distributed cognition framework have developed into a robust and extensive research paradigm in philosophy and cognitive science, departing from the traditional internalist view on mind and cognition (for an overview see Michaelian \& Sutton, 2013). Theorists working in this paradigm, broadly construed, have analyzed the relation between human cognitive systems and various cognitive artifacts, including maps, navigation systems, diagrams, notebooks, (scientific) models, (scientific) instruments, software programs, computer systems, and many more cognition-aiding artifacts. Artifacts supporting autobiographical remembering are notably lacking from this literature (but see Sutton, 2009a; Clowes, 2013, 2015). One possible explanation for the lack of focus on artifactual autobiographical remembering in the extended mind debate is that extended mind theorists are mainly concerned with practical cognitive tasks such as navigating, calculating, problem-solving, and so forth. In this sense, the extended mind is a view on human beings as adaptive problem solvers and as active agents acting in and on the world. While I agree with this anthropological view, there is no reason at all why the thesis, including the ontological and methodological commitments, should not extend to autobiographical memory capacities. 
Interestingly, because autobiographical memory has identity-constituting functions, arguing that autobiographical memory is extended and distributed pushes the extended mind thesis into debates about identity and self (see also, for example, Malafouris, 2008; Milojevic, 2020; Heersmink, 2018, 2020; Piredda \& Candiotto, 2019; but compare Wilson \& Lenart, 2014). Likewise, because autobiographical memories often have affective components, arguing that autobiographical memory is extended and distributed also pushes the extended mind thesis into debates about (extended) emotion and affect (e.g., Carter, Gordon \& Palermos, 2016; Colombetti \& Roberts, 2015; Krueger \& Szanto, 2016). The extended autobiographical memory thesis can thus build novel bridges to other fields in philosophy and psychology. Finally, while other animal species use environmental structures to aid their cognition (Cheng, 2018), using objects to remember one's personal past is a possibly unique form of human cognitive tool-use. Some animals, for example, use scent trails to navigate, but to the best of my knowledge, there is no literature on animals using objects to remember their personal past.

\section{3 | AUTOBIOGRAPHICAL MEMORY}

Before describing some of the properties of autobiographical memory, it is helpful to place it in a broader context by briefly taxonomizing human memory into various subsystems (Squire, 2009) (see Figure 1). A first distinction is between short-term and long-term memory. Most people can keep approximately four to five items in their short-term memory for several seconds up to a minute. Short-term memory is used during many tasks such as reading, calculating, navigating, cooking, conversing, and problem-solving, thereby playing a central role in many our cognitive activities. Long-term memory is divided in declarative and non-declarative memory. Declarative memories can be articulated, whereas non-declarative memories typically remain under the threshold of consciousness and have to do with performing procedural tasks like driving a car or tying your shoelaces.

Declarative memories, in turn, are also divided in two categories, namely semantic and episodic. Semantic memories are memories of general knowledge and facts, for example remembering that Canberra is the capital of Australia. Episodic memories are memories of one's past actions, thoughts, feelings, and experiences, for example remembering having a really spicy curry when you were in Canberra last week. When we remember our past episodically we reexperience a past event. With reexperience I mean figuratively travelling back in time and

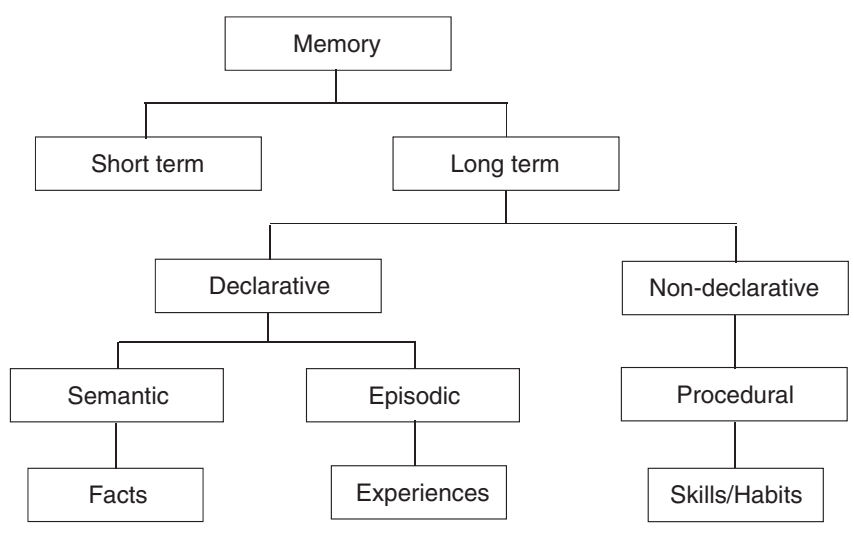

FIGURE 1 A taxonomy of human memory systems. The focus in this paper is on how evocative objects extend semantic and episodic memory systems, thereby allowing us to remember our personal past in a more detailed and reliable manner 
reconstructing an experience, typically involving a visual component (Tulving, 2002). Episodic remembering thus has a distinct phenomenology that is lacking in semantic memory (Tulving, 1985).

Our personal past can be remembered semantically and episodically. I therefore prefer the more general term of autobiographical memory to the more specific term of episodic memory. Episodic memories are experiential memories of specific episodes, whereas autobiographical memory also includes propositional/semantic memories of our personal past such as knowing that I went to the office 2 weeks ago without having specific experiential memories of being there. Autobiographical memory is thus a broader category than episodic memory. I will be neutral about whether autobiographical memory is a distinct system or composed of multiple systems, but I lean towards the latter. Following Kirk Michaelian (2016), I will use autobiographical memory as a capacity to remember our personal past.

Human autobiographical memory is not like an archive in which specific memories are stored and then later retrieved with the exact same content (Brockmeier, 2015; Schechtman, 1994; Sutton, 2009b). Instead, the contents and valences of autobiographical memories change over time. Detail is lost and every time a memory is retrieved it is reconstructed and restored with a slightly different content. This is consistent with a connectionist view on memory. Connectionism suggests that memory traces are stored across a pattern in the units of a network (Sutton, 1998). The connection weights between the units (i.e., neurons) store the content of the memory trace. Traces for different memories are not stored separately and isolated from each other but share some of the weights between the units. McClelland and Rumelhart put it as follows:

We see the traces laid down by the processing of each input as contributing to the composite, superimposed memory representation. Each time a stimulus is processed, it gives rise to a slightly different memory trace-either because the item itself is different or because it occurs in a different context that conditions its representation-the traces are not kept separate. Each trace contributes to the composite, but the characteristics of particular experiences tend nevertheless to be preserved, at least until they are overridden by cancelling characteristics of other traces. Also, the traces of one stimulus pattern can coexist with the traces of other stimuli, within the same composite memory trace (McClelland \& Rumelhart, 1986, p. 193; Sutton, 2009b).

Over time, the connection weights can be weakened and some of the content of the memory trace may then be lost. Importantly, because biological memory is malleable and changes over time, we need the informational stability provided by the artifactual environment to reliably remember our personal past (Sutton, 2009b). Information in objects such as photos usually remains fixed and we can lock on to that information at various times in our lives to use the stability, detail, and reliability of such objects to remember our past. Importantly, when using informational objects to remember our past, we do not retrieve and reconstruct a complete internal memory, rather information in the brain and in the object is integrated as to reconstruct an autobiographical memory. In this sense, the information we use to remember our personal past is distributed across embodied brains and the environment.

Lastly, autobiographical memory intersects with evaluative and affective systems in at least two ways (Holland \& Kensinger, 2010). First, the way we currently feel influences the types of memories we retrieve and reconstruct. When we feel positive, we tend to retrieve more positive memories, and when we feel negative we tend to retrieve more negative memories. This phenomenon is referred to as "mood-congruent memory." We look back on our past differently when feeling nostalgic, moody, or content. So, we look at our personal past through the affective lens of the present. Second, evaluative and affective states can be part of the content of an 
autobiographical memory. It is not the case that we first construct an autobiographical memory and then have an emotional response to it. Instead, the cognitive and affective components are interwoven. Some of our personal memories are affectively neutral and lack any phenomenology (e.g., that you went to the supermarket last week), whereas others are imbued with existential meaning, affect, and may have a rich phenomenology (e.g., your PhD graduation). So, when we retrieve an affectively laden autobiographical memory, it can make us feel a certain way. Remembering your father's funeral, for example, may cause you to feel sad, but remembering that city trip to Barcelona makes you feel joyful.

\section{4 | EVOCATIVE OBJECTS AND LIFELOGGING}

In this section, I propose a distinction between "cognitive artifacts" and "evocative objects." A cognitive artifact is a material object or structure that functionally contributes to performing a practical cognitive task such as navigating, calculating, planning, decision-making, and problem-solving (Fasoli, 2018; Heersmink, 2016). Examples of cognitive artifacts include maps, labels, abacuses, diaries, indexes, search engines, diagrams, models, and computer systems. Using such external artifacts often enhances our cognitive capacities, making cognitive tasks easier, faster, more reliable, or possible at all. Such artifacts have informational properties and functions that complement those of the embodied brain and have been the focus of most extended mind theorizing.

An evocative object, by contrast, is an object or structure that intentionally or unintentionally aids us in remembering our personal past (Turkle, 2007; Heersmink, 2018; Heersmink \& McCarroll, 2019; for discussion see Piredda, 2020). Examples include photos, videos, souvenirs, postcards, concert tickets, journals, books, works of art, trophies, inherited objects, shells found on the beach, and many other mementos. Interacting with such objects activate cognitive processes that reconstruct and retrieve the contents of personal memories into consciousness. This is sometimes done intentionally, for example when we browse through our photos on our smartphone or computer. But it also happens unintentionally, for example, when packing a suitcase, it may unexpectedly remind us of a previous holiday. A photo is autobiographically meaningful because it is representational, whereas the suitcase is autobiographically meaningful because of an accidental association between the object and a memory. The evocative powers of objects can thus come about through both representational and nonrepresentational properties.

The boundaries between these two categories of material culture are fluid and porous. The abacus I used in elementary school to learn to calculate may now function as an evocative object to remind me of my time as a schoolchild. A cognitive artifact can also simultaneously be an evocative object, being a member of both categories. For example, someone's notebook/journal may contain autobiographical descriptions about past events and experiences but may also contain semantic information used to plan a future work trip. The distinction between cognitive artifacts and evocative objects is thus perhaps best understood as different ways of using information, rather than as strict categories of artifacts.

More specifically, the distinction is about which types of cognitive processes the artifact or object contributes to or extends. Cognitive artifacts contribute to practical cognitive tasks such as navigating, calculating, planning, decision-making, and problem-solving, whereas evocative objects contribute to autobiographical remembering. In this sense, an evocative object is still a cognitive artifact, in that it contributes to cognitive processes. However, because 
autobiographical remembering is a distinct type of cognitive process, objects contributing to this process have an existential and sometimes affective dimension that is lacking in regular cognitive artifacts. Importantly, because autobiographical remembering plays a central role in maintaining our narrative identity (Schechtman, 1994), I think evocative objects are a unique sort of cognitive artifact, deserving their own label. There is interesting recent work done on "affective artifacts," which "are tentatively defined as objects that have the capacity to alter the affective condition of an agent, and that in some cases play an important role in defining that agent's self' (Piredda, 2020, p. 549). Some (but not all) evocative objects can be seen as affective artifacts, as they can alter the affective state of the agent.

Evocative objects can aid us in remembering our personal past in a way that is quite different from remembering our past without the aid of such objects. When thinking back to my 2018 holiday in Lombok, Indonesia, I know that and when I went to Lombok and I am able to retrieve a few specific episodic/experiential memories. However, when browsing through my digital photo album containing over a hundred photos, I am not just able to recall many more experiences and events but I can do so with much more detail, reliability, and in a more chronologically accurate manner. In this sense, interacting with evocative objects can thus enhance autobiographical memory processes.

An important technology to create evocative objects is SenseCams (Hodges et al., 2006). These are small wearable cameras worn around one's neck with a lanyard, designed to help people capture and remember their daily activities. SenseCams have an ultra-wide angle lens, maximizing the amount of information captured by the camera. It automatically takes photos without the agency of the user when its internal sensors detect a change in environmental conditions (e.g., light intensity, GPS location), but also has a trigger button that can be used to take a photo. These photos are uploaded onto a computer and viewed using a simple interface. Since their introduction in 2006, SenseCams have been used by cognitively healthy people and people with memory disorders like dementia and amnesia. These devices are often used by lifeloggers, which are people who use technology to record and store information about their activities into a lifelog (Bell \& Gemmell, 2009). This recent trend in lifelogging is becoming increasingly popular across all demographic groups (Lupton, 2016) and is one of the most powerful tools for augmenting human autobiographical memory.

Gordon Bell and Jim Gemmell, computer scientists and pioneers in lifelogging, predict that lifelogs "will become vital to our episodic memory. As you live your life, your personal devices will capture whatever you decide to record. Biomemories fade, vanish, merge, and mutate with time, but your digital memories are unchanging" (Bell \& Gemmell, 2009, p. 57). So, because human biological memory is malleable and prone to changing over time, lifelogs can provide the stability, detail, and reliability as to remember our past in a more reliable and detailed manner. Bell and Gemmell's approach to lifelogging is characterized by a "total capture" of our lives and a "total recall" of our personal past. Their goal is to build a lifelog that contains as much information as possible about one's personal past. However, one may wonder whether this is the right way to do it (Sellen \& Whittaker, 2010). Human autobiographical memory is selective for a reason: We do not need to remember our entire life in great detail as it would clutter our memory system. We remember our past in terms of an unfolding narrative, which is not like a film we can play back in detail but only contains a number of self-defining experiences (Schechtman, 1994). Bell and Gemmell's "total capture" and "total recall" approach runs the risk of cluttering our external memory. Rather, we need to construct a lifelog that selectively supports important autobiographical memories (CreteNishihata et al., 2012). 


\section{5 | AUTOBIOGRAPHICAL DEPENDENCY}

Having outlined complementarity-based extended mind theory, described some of the properties of autobiographical memory, and discussed some research on evocative objects and lifelogging, I will now continue with presenting the dimension of autobiographical dependency. This will help us in better understanding the integration between biological memory systems and evocative objects. This dimension can be characterized as the degree to which we depend on an evocative object to be able to remember a past event or experience. To better understand the underlying conceptual structure of this dimension, two elements are relevant: (a) the cognitive profile of the embodied agent; and (b) the informational and functional properties of the evocative object. The degree of autobiographical dependency emerges out of the interaction between these two elements. Autobiographical dependency can be seen as a spectrum and below I discuss three points on this spectrum, which I characterize as low, moderate, and strong.

When autobiographical dependency is low, we can still relatively easily remember the experience or event without needing an evocative object to aid our memory. For example, the day after our PhD graduation ceremony, episodic/experiential memories of the event are still vivid and detailed, in part because the event is recent and in part because it is emotionally significant. At this point in time, we do not need to look at photos or videos of the event in order to be able to remember it, although viewing photos or videos may fill in some details we missed. We can still clearly remember the gist of the dean's speech, who was there with us, what the theatre looked like, how long the event took, how we felt emotionally, how uncomfortable the academic gown felt, where we went for dinner afterwards, and so forth. In most cases, the more recent a memory, the easier it is to remember. But as time passes, we often lose detail in our episodic/experiential memories.

Cognitive psychologists distinguish between a memory being available and accessible (Tulving \& Pearlstone, 1966). When a memory is available, it is consolidated and stored in the brain. When it is accessible, we are able to retrieve and reconstruct the contents of the memory into consciousness. Sometimes memories are available but not accessible. This happens to all of us, for example, when we experience the tip-of-the-tongue-phenomenon. Inaccessibility of memories happens most often with people suffering from memory disorders like dementia or amnesia who may have difficulty activating retrieval processes. So, availability has to do with storage systems, whereas accessibility has to do with retrieval systems. When autobiographical dependency is low, memories are both available and easily accessible, and so we do not need evocative objects to aid our recall. Over time, though, the availability decreases, as the strength of the connection weights in the neural networks may weaken.

Autobiographical dependency is moderate when we can still remember parts of the event or experience but need to interact with an evocative object to have a fuller, more detailed memory of the event. Some years after our PhD graduation ceremony, we may be able to retrieve a number of specific episodic/experiential memories. Perhaps we can still remember the more emotionally salient features of the experience and event such as who was there with us and the sense of pride and accomplishment we felt, but we may not be able to remember less salient details anymore such as the dean's speech, what the theatre looked like, and where we went for dinner afterwards. However, when we look at the photos and video of the event, those parts of the event may come back to us and we may reexperience them. When autobiographical dependency is moderate, memories may have lost some of their detail and so the availability is somewhat diminished, and the memories may also be less easily accessible. In such cases, evocative objects may help us in recalling the personal past by proving information that is no longer available in the brain. 
When autobiographical dependency is strong, we need to interact with an evocative object in order to remember an event or experience. Many years after our PhD graduation ceremony, our episodic/experiential memories of the event will most likely be (very) weak. Perhaps we may not have any episodic/experiential memories of the event at all, but only remember that we had a PhD graduation ceremony. However, when looking at the photos and videos of the event, some of the details may come back to us. When autobiographical dependency is strong, memories may have lost most, if not all, of their detail and emotional content, in which case the availability is quite diminished and the content that is still there may be difficult to access. In such cases, we need an evocative object to be able to retrieve an autobiographical memory, suggesting that when interacting with such evocative objects both the vehicles and processes of remembering our personal past are distributed across the embodied agent and the evocative object. In such cases, evocative objects do not merely trigger a complete biological memory but contribute to reconstructing a memory by combining information stored in connectionist networks in the embodied brain and in an evocative object. The stronger the dependency, the more the equilibrium of information-storage shifts towards the artifactual. ${ }^{2}$

Autobiographical dependency typically increases when trying to remember an event that is deeper in our past, as the memory trace may decay over time. It also increases when people have memory disorders like dementia or amnesia. For example, people with anterograde amnesia have an inability to properly consolidate new autobiographical memories, which often happens after an accident or brain damage. Such patients can use evocative objects to aid them in remembering their activities. Rather than storing personal memories in their brain, they can store these in a lifelog by using a SenseCam (Loveday \& Conway, 2011). Consider Patrick Jones, an extreme case of autobiographical dependency, described by Gary Marcus (2008). Jones, who suffers from a severe form of anterograde amnesia, uses Evernote (a program allowing him to make and access notes) and Curio (a mind mapping program allowing him to draw connections between interconnected thoughts) on his mobile computing device and desktop computer. He uses these software programs to create a lifelog of his past activities, including notes about what he has done and who he talked to and why. Jones's improvised lifelogging system plays a key role in his autobiographical memory and cognitive life more generally (Clowes, 2013).

In his case, retrieving an autobiographical memory from his lifelog lacks an episodic/experiential component. Because his episodic memory is so damaged due to a brain injury, he cannot consolidate and retrieve an experience. Instead, retrieving information from his lifelog is purely semantic, providing knowledge-that about his past. Jones's autobiographical dependency on his lifelogging system is extremely strong. He cannot consolidate new memories in his brain and therefore needs lifelogging technology to perform this function for him, literally substituting his memory systems.

\section{6 | AGENT-LIFELOGGING SYSTEMS}

We have now looked at autobiographical dependency, but how do some of the other dimensions of integration mentioned in Section 2 (such as information flow, accessibility, durability,

\footnotetext{
${ }^{2} \mathrm{~A}$ reviewer pointed out that a difference between biological and artifactual memory is that artifactual can be more easily hacked than biological memory. In relation to the dimension of autobiographical dependency, it is noteworthy to point out that the higher the dependency on the object, the more vulnerable we are to hacking and manipulation of our extended memories. This has consequences for informational privacy and other moral values.
} 
trust, procedural transparency, informational transparency, and personalization) come into play when using lifelogs? In this section, I will do a brief case study where each dimension is ranked in terms of three categories: low, medium, and high. When users interact with their lifelogs, the information flow is two-way: They upload information (videos, photos, notes, GPS locations, etc.) into their lifelog and then retrieve it at some later point. Accessibility is high as lifelogs are typically stored in the cloud and can be accessed on a variety of computing devices, including wearable devices like tablets and smartphones. Durability is medium to high as most lifeloggers spend quite some time interacting with their lifelog, they frequently couple with their lifelog and will do so over a long period of time (Bell \& Gemmell, 2009). Trust is high as the contents of the lifelogs are uploaded by the user, the user therefore knows the information to be true and thus trustworthy. There is usually no reason to distrust the information in one's lifelog, it is accepted without consciously evaluating it.

Procedural transparency is typically high as the devices and software programs allowing one to browse through the contents of one's lifelog are easy to use. But this does depend on the design of the particular interface, some users have reported that it is difficult to find the right entry, as some lifelogs have more than a million photos (Caprani, O'Connor \& Gurrin, 2013). But much progress is being made in interface design (e.g., Lee et al., 2008). Informational transparency is high as interpreting the contents of lifelogs is relatively straightforward, mainly because the information is about one's own life and experiences, and is created by the user him or herself.

Personalization is high as the lifelog contains information pertaining to the user's life and experiences, lifelogs are probably one of the most personalized technologies. Also, lifelogs are actively edited which involves deleting irrelevant information and selecting relevant information, which further increases the personalization. For some users, lifelogs may become entrenched, meaning that the user and object transform each other's properties: The information in the lifelog may create insights into one's behavior (e.g., realizing that one is not exercising enough) that may lead to changes in those behaviors. Autobiographical dependency is typically medium, but this depends on the particular entry one is viewing in the lifelog. If it concerns an entry representing a recent event, it is likely that the user may still be able to remember the event without viewing the entry. But if it is an event deeper in the past or one that is less emotionally salient, then it may be the case that the user would have difficulty remembering the event without using the lifelog (Sellen et al., 2007).

When artifacts are highly personalized, which is the case with evocative objects and lifelogs, we often trust them more. "When one trusts external informational sources, one grants them a similar cognitive status as one's own memory and other internal cognitive resources" (Nguyen, forthcoming). Given that photos and lifelogs are often more reliable than biological memory, it is rational to put a lot of trust in the contents of one's lifelogs. We do not consciously evaluate the contents of our lifelogs but automatically accept them as true. Our default disposition is not to question the truth-value of the information in our lifelog but implicitly accept it as true. This is so because if information is included in our lifelog, then it must be about an event we experienced ourselves.

Overall, then, lifelogs rank high on most dimensions and are thus deeply integrated into the memory systems of their users, suggesting that both the vehicles and processes of remembering our personal past are distributed, in that way constituting a new systemic whole. To better understand such new systemic wholes, we need to enlarge the unit of analysis in the study of autobiographical remembering and focus on agent-object interactions. Lifelogging technologies and other wearable computing devices have all the hallmarks of extended and distributed 
cognitive systems. Clark (2007) points out that: "As we move towards an era of wearable computing and ubiquitous information access, the robust, reliable information fields to which our brains delicately adapt their routines will become increasingly dense and powerful, further blurring the distinction between the cognitive agent and her best tools, props and artifacts" (p. 275). As the recent trends in lifelogging, mobile computing, and artificial intelligence continue and converge, it will result in new applications that will be easier to use, are more personalized, and more computationally powerful. The cognitive functions of such computational artifacts and systems will be integrated deeper into a broader spectrum of our cognitive capacities, including our capacity to remember our personal past.

At this point, a critic might ask: Why should resources that are deeply integrated into the memory systems of their users, be seen as constitutive parts of those systems, rather than as merely casually integrated to prompt or cue memories? There are two possible responses to this criticism, related to both semantic and episodic memories. First, when the autobiographical dependency is high, semantic memories can be stored in external media without triggering a biological memory. The information in Jones's lifelog, for example, is not also stored in his brain, rather it is stored only in the lifelog because he has difficulty consolidating new memories in his brain. For this reason, the information in the lifelog does not trigger an internal memory but literally is Jones's memory. So, the information in his lifelog is part of the physical system that realizes some of his memories, which thus supervene on the Jones-plus-lifelog system.

A reviewer noted that Jones does not recognize the retrieved memory as his, which undermines the status of external memory as real memory. My view is that it is more important how the external memory is caused, rather than recognizing it as our own. I support a liberal version of the causal theory of memory. The causal theory of memory claims that biological memory traces need to be caused appropriately by an experience (Martin \& Deutscher, 1966; Bernecker, 2008, 2010; for discussion see Robins, 2016). On this view, an experience needs to be consolidated in a biological trace for it to count as memory. This causal condition allows us to distinguish real memory from imagining or confabulating. In Jones's case, he has an experience which is first temporarily stored in his short-term memory and then offloaded onto his lifelogging system. So there is still a relevant causal link between an experience and an external memory. Why would it matter where the trace is stored, if it is caused by the person in the right sort of way. So, a more liberal reading of the causal condition might include external memories as real memories (see also Sutton \& Windhorst, 2009).

Jones is of course an extreme example, but many of us store and rely on semantic memories in artifacts that are not also stored in our own biological memory. We may sometimes look up an appointment in our diary without remembering putting it in there or we may read an entry in our journal about a past event that we completely forgot. So, the capacity to semantically remember our personal past does not always involve triggering internal memories, rather sometimes semantic memories are only stored in the environment. In extreme cases like Jones's, lifelogging technology has substituted his biological memory processes altogether. His biological memory is so poor that technology has fully replaced the encoding, storage and retrieval capacities usually done by biological memory systems. Semantic memories, then, are not triggered in biological memory but are fully constituted by information in artifacts.

Second, when the autobiographical dependency is high, an object goes beyond merely triggering a fully formed episodic memory. Rather, the information it contains helps to reconstruct an episodic memory in a way that is not possible without the object. As we have seen, when the autobiographical dependency is low, memories are both available and easily accessible, and so we do not need evocative objects to aid our recall. But when autobiographical dependency is 
strong, biological memories may have lost most, in some cases perhaps all, of their detail and emotional content, in which case the availability is quite diminished and the content that is still there may be difficult to access. Evocative objects such as (SenseCam) images can aid us in accessing what is still stored and to use the information in the brain and information in an object to reconstruct a much fuller memory with more detail, thereby allowing us to remember our personal past in a way that is quite different from remembering our past without the aid of such objects (Loveday \& Conway, 2011). In such cases, evocative objects do not merely trigger a fully formed biological memory but contribute to reconstructing a memory by combining information stored in connectionist networks in the brain and in an evocative object.

Let me end this paper with a brief normative note. Socrates worried that writing restructures our biological memory in undesirable ways, arguing that when we can write things down, we will not store them in our brain, resulting in less knowledgeable thinkers. Like many other memory technologies, it is very likely that evocative objects restructure the biological memory systems and processes of their users. Knowing that lifelogs provide reliable access to trustworthy and detailed information about one's past activities may result in consolidating that information less strongly in the brain, increasing the autobiographical dependency. Linda Henkel (2014) has performed a study showing that when people take photos of museum objects, they have less detailed memories of those objects as compared to people who did not take a photo of the object. The process of taking a photo thus interferes with attentional processes which has downstream effects on encoding, consolidating, and retrieving. If lifelogging becomes more prevalent in the (near) future, a new equilibrium between biological and artifactual autobiographical memory may come about, one in which information-storage shifts slowly towards the artifactual (Heersmink, 2017). Further philosophical and ethical analysis can contribute to better understanding this process, allowing us to develop a relation to evocative objects and lifelogging that is consistent with our personal, moral, and cultural values.

\section{7 | CONCLUSION}

In this paper, I argued that autobiographical memory is extended and distributed across embodied brains and evocative objects. When interacting with evocative objects, we typically integrate information in the brain and in the world to reconstruct an autobiographical memory, thereby allowing us to remember our personal past in a way that is quite different from remembering our past without the aid of evocative objects. The more we depend on objects to remember our personal past, the more the equilibrium of information-storage shifts towards the artifactual, and the deeper they are integrated into our biological memory systems. Conceptualizing autobiographical memory as extended and distributed extends the thesis into debates about identity, self, and emotion, and allows us to better understand a possibly unique form of human cognitive tool-use. It is thus a fruitful topic for further exploration.

\section{ACKNOWLEDGEMENTS}

I am very grateful for the comments of two anonymous reviewers. I would also like to thank Giulia Piredda and Marco Fasoli for the invitation to give an online seminar on this paper at the Center for Neurocognition, Epistemology, and Theoretical Syntax in Pavia, Italy.

\section{ORCID}

Richard Heersmink (D) https://orcid.org/0000-0002-0102-0308 


\section{REFERENCES}

Bell, G. \& Gemmell, J. (2009). Total recall: How the e-memory revolution will change everything. New York, NY: Dutton.

Bernecker, S. (2008). The metaphysics of memory. Dordrecht: Springer.

Bernecker, S. (2010). Memory: A philosophical study. Oxford: Oxford University Press.

Brockmeier, J. (2015). Beyond the archive: Memory, narrative, and the autobiographical process. Oxford: Oxford University Press.

Caprani, N., O'Connor, N. \& Gurrin, C. (2013). Experiencing SenseCam: A case study interview exploring seven years living with a wearable camera. SenseCam'13: Proceedings of the 4th International SenseCam and Pervasive Imaging Conference. pp. 52-59.

Carter, J. A., Gordon, E. C. \& Palermos, S. O. (2016). Extended emotion. Philosophical Psychology, 29(2), 198-217.

Colombetti, G. \& Roberts, T. (2015). Extending the extended mind: The case for extended affectivity. Philosophical Studies, 172(5), 1243-1263.

Clark, A. (1989). Microcognition. Cambridge, MA: MIT Press.

Clark, A. (2007). Re-inventing ourselves: The plasticity of embodiment, sensing, and mind. Journal of Philosophy and Medicine, 32(3), 263-282.

Clark, A. (2008). Supersizing the mind: Embodiment, action, and cognitive extension. Oxford: Oxford University Press.

Clark, A. \& Chalmers, D. (1998). The extended mind. Analysis, 58(1), 10-23.

Clowes, R. (2013). The cognitive integration of e-memory. Review of Philosophy \& Psychology, 4(1), 107-133.

Clowes, R. (2015). Thinking in the cloud: The cognitive incorporation of cloud-based technology. Philosophy \& Technology, 28(2), 261-296.

Cheng, K. (2018). Cognition beyond representation: Varieties of situated cognition in animals. Comparative Cognition and Behaviour Reviews, 13, 1-20.

Crete-Nishihata, M., Baecker, R. M., Massimi, M., Ptak, D., Campigotto, R., Kaufman, L. D., ... Black, S. E. (2012). Reconstructing the past: Personal memory technologies are not just personal and not just for memory. Human-Computer Interaction, 27(1-2), 92-123.

Fasoli, M. (2018). Substitutive, complementary and constitutive cognitive artifacts: Developing an interactioncentered approach. Review of Philosophy and Psychology, 9(3), 671-687.

Gallagher, S. (2018). The extended mind: State of the question. Southern Journal of Philosophy, 56(4), 421-447.

Harris, C., Barnier, A., Sutton, J. \& Keil, P. (2014). Couples as socially distributed cognitive systems: Remembering in everyday social and material contexts. Memory Studies, 7(3), 285-297.

Heersmink, R. (2015). Dimensions of integration in embedded and extended cognitive systems. Phenomenology and the Cognitive Sciences, 14(3), 577-598.

Heersmink, R. (2016). The metaphysics of cognitive artefacts. Philosophical Explorations, 19(1), 78-93.

Heersmink, R. (2017). Distributed selves: Personal identity and extended memory systems. Synthese, 194(8), $3135-3151$.

Heersmink, R. (2018). The narrative self, distributed memory, and evocative objects. Philosophical Studies, 175 (8), 1829-1849.

Heersmink, R. (2020). Narrative niche construction: Memory ecologies and distributed narrative identities. Biology and Philosophy, 35(5), 1-24.

Heersmink, R. \& McCarroll, C. (2019). The best memories: Identity, narrative and objects. In T. Shanahan \& P. Smart (Eds.), Blade runner 2049: A philosophical exploration (pp. 87-107). London: Routledge.

Heinrich, J. H. (2018). Neuroethics, cognitive technologies and the extended mind perspective. Neuroethics. https://doi.org/10.1007/s12152-018-9365-8

Henkel, L. (2014). Point-and-shoot memories: The influence of taking photos on memory for a museum tour. Psychological Science, 25(2), 396-402.

Hodges, S., Williams, L., Berry, E., Izadi, S., Srinivasan, J., Butler, A., ... Wood, K. (2006). SenseCam: A retrospective memory aid. In P. Dourish \& A. Friday (Eds.), Ubicomp 2006: Ubiquitous computing (pp. 177-193). Berlin: Springer.

Holland, E. \& Kensinger, A. (2010). Emotion and autobiographical memory. Physics of Life Reviews, 7(1), 88-131.

Hutchins, E. (1995). Cognition in the wild. Cambridge: MIT Press. 
Krueger, J. \& Szanto, T. (2016). Extended emotions. Philosophy Compass, 11(12), 863-878.

Lee, H., Smeaton, A., O'Connor, N., Jones, G., Blighe, M., Byrne, D., ... Gurrin, C. (2008). Constructing a SenseCam visual diary as a media process. Multimedia Systems, 14(6), 341-349.

Loveday, C. \& Conway, M. (2011). Using SenseCam with an amnesic patient: Accessing inaccessible everyday memories. Memory, 19(7), 697-704.

Lupton, D. (2016). The quantified self: A sociology of self-tracking. Cambridge, MA: Polity Press.

Malafouris, L. (2008). Between brains, bodies and things: Tectonoetic awareness and the extended self. Philosophical Transactions of the Royal Society B, 363, 1993-2002.

Marcus, G. (2008). What if HM had a blackberry? Coping with amnesia. Using Modern Technology. Psychology Today. Retrieved from https://www.psychologytoday.com/au/blog/kluge/200812/what-if-hm-had-blackberry

Martin, C. \& Deutscher, M. (1966). Remembering. Philosophical Review, 75(2), 161-196.

McClelland, J. \& Rumelhart, D. (1986). A distributed model of human learning and memory. In J. McClelland \& D. Rumelhart (Eds.), Parallel distributed processing: Explorations in the microstructure of cognition (Vol. 2, pp. 170-215). Cambridge, MA: MIT Press.

Menary, R. (2007). Cognitive integration: Mind and cognition unbounded. London: Palgrave McMillan.

Michaelian, K. (2016). Mental time travel: Episodic memory and our knowledge of the personal past. Cambridge, MA: MIT Press.

Michaelian, K. \& Sutton, J. (2013). Distributed cognition and memory research: History and current directions. Review of Philosophy and Psychology, 4(1), 1-24.

Milojevic, M. (2020). Extended mind, functionalism, and personal identity. Synthese, 197(5), 2143-2170.

Nguyen, C. (forthcoming). Trust as an unquestioning attitude. In Oxford studies in epistemology. Oxford: Oxford University Press.

Piredda, G. (2020). What is an affective artifact? A further development in situated affectivity. Phenomenology and the Cognitive Sciences, 19(3), 549-567.

Piredda, G. \& Candiotto, L. (2019). The affectively extended self: A pragmatist approach. Humana Mente Journal of Philosophical Studies, 12(36), 121-145.

Robins, S. (2016). Representing the past: Memory traces and the causal theory of memory. Philosophical Studies, 173(11), 2993-3013.

Rowlands, M. (1999). The body in mind: Understanding cognitive processes. Cambridge, MA: Cambridge University Press.

Schechtman, M. (1994). The truth about memory. Philosophical Psychology, 7(1), 3-18.

Sellen, A., Fogg, A., Aitken, M., Hodges, S., Rother, C. \& Wood, K. (2007). Do life-logging technologies support memory for the past? An experimental study using SenseCam. In Proceedings of the conference on human factors in computing systems (pp. 81-90). New York, NY: ACM Press.

Sellen, A. \& Whittaker, S. (2010). Beyond total capture: A constructive critique of lifelogging. Communications of the ACM, 53(5), 70-77.

Squire, L. (2009). Memory and brain systems: 1969-2009. The Journal of Neuroscience, 29(41), 12711-12716.

Sterelny, K. (2010). Minds: Extended or scaffolded? Phenomenology and the Cognitive Sciences, 9(4), 465-481.

Sutton, J. (1998). Philosophy and memory traces: Descartes to connectionism. Cambridge, MA: Cambridge University Press.

Sutton, J. (2009a). The feel of the world: Exograms, habits, and the confusion of types of memory. In A. Kania (Ed.), Philosophers on memento (pp. 65-86). London: Routledge.

Sutton, J. (2009b). Remembering. In P. Robbins \& M. Aydede (Eds.), The Cambridge handbook of situated cognition (pp. 217-235). Cambridge, MA: Cambridge University Press.

Sutton, J. (2010). Exograms and interdisciplinarity: History, the extended mind, and the civilizing process. In R. Menary (Ed.), The extended mind (pp. 189-225). Cambridge, MA: MIT Press.

Sutton, J. \& Windhorst, C. (2009). Extended and constructive remembering: Two notes on Martin and Deutscher. Crossroads: An Interdisciplinary Journal for the Study of History, Philosophy, Religion and Classics, 4(1), 79-91.

Tulving, E. (1985). Memory and consciousness. Canadian Psychology/Psychologie Canadienne, 26(1), 1-12.

Tulving, E. (2002). Episodic memory: From mind to brain. Annual Review of Psychology, 53(1), 1-25.

Tulving, E. \& Pearlstone, Z. (1966). Availability versus accessibility of information in memory for words. Journal of Verbal Learning and Verbal Behavior, 5(4), 381-391. 
Turkle, S. (Ed.) (2007). Evocative objects: Things we think with. Cambridge, MA: MIT Press.

Wegner, D. (1986). Transactive memory: A contemporary analysis of the group mind. In B. Mullen \& G. Goethals (Eds.), Theories of group behaviour (pp. 185-208). New York, NY: Springer.

Wheeler, M. (2011). In search of clarity about parity. Philosophical Studies, 152(3), 417-425.

Wilson, R. (2004). Boundaries of the mind: The individual in the fragile sciences. Cambridge, MA: Cambridge University Press.

Wilson, R. \& Clark, A. (2009). How to situate cognition: Letting nature take its course. In P. Robbins \& M. Aydede (Eds.), The Cambridge handbook of situated cognition (pp. 55-77). New York, NY: Cambridge University Press.

Wilson, R. \& Lenart, B. (2014). Extended mind and identity. In J. Clausen \& N. Levy (Eds.), Handbook of neuroethics (pp. 423-439). Dordrecht: Springer.

How to cite this article: Heersmink R. Extended mind and artifactual autobiographical memory. Mind \& Language. 2020;1-15. https://doi.org/10.1111/mila.12353 